\title{
ACUTE ABDOMEN IN PREGNANCY- A DESCRIPTIVE STUDY
}

\author{
Neeta Sarma ${ }^{1}$, Bikash Sandalya ${ }^{2}$
}

${ }_{1}^{1}$ Assistant Professor, Department of Obstetrics and Gynaecology, Silchar Medical College, Ghungoor, Cachar, Assam, India. ${ }^{2}$ Assistant Professor, Department of General Surgery, Silchar Medical College, Ghungoor, Cachar, Assam, India.

\section{BACKGROUND}

\section{ABSTRACT}

Acute abdomen during pregnancy is often worrisome for an obstetrician owing to the diagnostic and management challenges. A strong index of suspicion, clinical expertise and a multidisciplinary approach can go a long way to tackle such cases.

The aim of this study is to analyse the presenting clinical features and the causes of acute pain abdomen during pregnancy and the management of such cases.

\section{MATERIALS AND METHODS}

A descriptive study was performed on 55 pregnant women presenting with acute pain abdomen admitted in Silchar Medical College and Hospital between July 2016 and June 2018. A detailed history and a thorough clinical examination was done. Women with labour pains were excluded from the study. The necessary investigations apart from the routine antenatal tests were carried out. Ultrasonography was performed in all. MRI was done when feasible or when diagnosis was unclear. Case management was individualised, and surgical and medical team involvement was made whenever needed. Surgical intervention was taken if indicated. All women were followed up. Data was analysed with Microsoft Excel.

\section{RESULTS}

$41.8 \%, 32.7 \%$ and $25.5 \%$ of the women were of the age group of 25 to 31 years, 18 to 24 years and 32 to 38 years respectively. 49.1\% were Muslims, 20\% were Hindus and 14.5\% were Christians. $34.5 \%$ were booked cases. $81.8 \%$ were from rural areas. $36.4 \%$ of patients each presented with pain in the second and third trimester of pregnancy. The presenting symptoms were pain $(100 \%)$, diminished appetite $(45.5 \%)$, nausea $(32.7 \%)$, bleeding per vagina $(27.3 \%)$, increased urinary frequency $(18.2 \%)$, backache $(18.2 \%)$, shortness of breath $(7.3 \%)$, diarrhoea $(3.6 \%)$ and constipation $(3.6 \%)$. In $89.1 \%$ women, pain was of less than 24 hours duration. $45.5 \%, 40 \%$ and $14.5 \%$ came with diffuse, lower and upper abdominal pain respectively. 87.3\% complained of continuous dull pain, while $10.9 \%$ had intermittent, colicky pain. Anaemia (54.5\%) and hypotension (49.1\%) were the common associated findings. $29(52.7 \%)$ cases were diagnosed to have an obstetrical cause of pain which included ectopic pregnancy (27.6\%), miscarriage (20.7\%), molar gestation (17.2\%), ruptured uterus (17.2\%), abruptio placentae (10.3\%) and acute polyhydramnios (6.9\%). In $26(47.3 \%)$ cases the cause of pain abdomen was non-obstetrical which included acute appendicitis $(19.2 \%)$, acute cholecystitis (15.4\%), ureteric colic (15.4\%), acute urinary tract infection (11.5\%), acute pancreatitis $(7.7 \%)$, intestinal obstruction (7.7\%), acute peptic ulcer $(7.7 \%)$, torsion of ovarian tumour $(7.7 \%)$, blunt trauma with splenic rupture (3.8\%) and red degeneration of uterine fibroid (3.8\%). 82.8\% of the women with obstetrical cause required surgical management. Amongst the 26 cases with non-obstetrical origin of pain, 8 (30.8\%) underwent surgery- laparotomy (5) and laparoscopy (3). Significantly, higher number of surgeries were carried out in the second trimester $(\mathrm{p}<0.05)$. The complications among women with non-obstetrical abdominal pain were- wound infection and preterm labour, amongst those treated surgically; preterm labour and intrauterine foetal death, amongst those managed conservatively.

\section{CONCLUSION}

Acute abdomen in pregnancy poses a diagnostic and therapeutic dilemma to the obstetrician. Prompt diagnosis and management is critical in such situations.

\section{KEY WORDS}

Acute Abdomen, Pregnancy, Obstetrical, Non-Obstetrical.

HOW TO CITE THIS ARTICLE: Sarma N, Sandalya B. Acute abdomen in pregnancy- a descriptive study. J. Evolution Med. Dent. Sci. 2018;7(40):4366-4370, DOI: $10.14260 /$ jemds/2018/974

'Financial or Other Competing Interest': None.

Submission 09-08-2018, Peer Review 14-09-2018,

Acceptance 21-09-2018, Published 01-10-2018.

Corresponding Author:

Dr. Bikash Sandalya,

Assistant Professor,

Department of General Surgery,

Silchar Medical College, Ghungoor, Cachar

Masimpur, Assam,

India.

E-mail: bikashsandilya@gmail.com

DOI: $10.14260 /$ jemds $/ 2018 / 974$

\section{BACKGROUND}

Acute abdomen refers to an intra-abdominal process that is characterised by abdominal pain, tenderness and muscular rigidity, for which emergency surgery must be considered.[1] Acute abdomen in pregnancy remains one of the most challenging diagnostic and therapeutic dilemmas today.[2] An acute abdomen in pregnancy can be caused by pregnancy itself, be predisposed to by pregnancy or be the result of a purely incidental cause. ${ }^{[3]}$

The diagnostic work-up of an acute abdomen may be more difficult in pregnant than in non-pregnant women due to the normal anatomical and physiological changes that occur during pregnancy.[4] Non-obstetric surgical emergencies may be difficult to recognise in pregnant 
patients, whose normal physiologic state is altered by pregnancy.[5] Numerous physiologic changes in pregnancy may affect the presentation of abdominal pain in pregnancy. Acute abdominal pain in pregnant women poses a diagnostic challenge as gastrointestinal, genitourinary and gynaecologic diseases. They may all manifest with non-specific symptoms, which could lead to a delay in diagnosis. Guarding in the setting of peritonitis may not occur, because of loss of elasticity in the abdominal wall musculature.[6] Displacement of intra-abdominal organs including the appendix by the gravid uterus may also confound the clinical presentation.[6] The enlarged uterus may also compress the urinary tract leading to hydroureter and hydronephrosis. ${ }^{[7]}$ In addition the high progesterone concentration during pregnancy decreases lower oesophageal sphincter tone, small bowel and colonic motility, gallbladder emptying and ureteral tone.[8]

Missed diagnosis of these acute abdomens forms the basis of their gravity in terms of both maternal and foetal prognosis.[9] Delayed diagnoses and treatment may have more serious consequences for pregnant women than for other patients. ${ }^{[4]} \mathrm{A}$ high index of suspicion must be used when evaluating a pregnant patient with abdominal pain.[10] Requisite diagnostic imaging and interventions should be performed as indicated, since delay in diagnosis and treatment can increase maternal and foetal/ newborn morbidity and mortality.[11]

Graded compression ultrasonography is the preferred initial imaging technique to evaluate for acute appendicitis in pregnant patients, since it is safe and readily available.[12] CT carries the risks of radiation-induced carcinogenesis.[12] Use of computed tomography should not be delayed when there is a need for early diagnosis. MRI is the preferred second-line modality in the pregnant population, as it provides excellent soft-tissue resolution and anatomic detail.[12]

Moreover, the presence of a foetus may modify the management. It is well known that abdominal interventions in this period carry out a higher risk of miscarriage or premature labour.[13] Laparoscopic surgery should be performed in the second trimester when possible and appears as safe as laparotomy. Conservative management during pregnancy with surgical management postpartum appears reasonable in most cases.

The present study was done with an aim to evaluate the presenting clinical features and the causes of acute pain abdomen during pregnancy and the management of such cases.

\section{MATERIALS AND METHODS}

A descriptive study was performed in which fifty-five (55) pregnant women, irrespective of gestational age, presenting with acute pain abdomen requiring hospitalisation in the antenatal OPD or emergency labour room or casualty of Silchar Medical College and Hospital over a period of two years between July 2016 and June 2018 were included. A thorough history was taken. The onset, nature, location of pain with exacerbating or relieving factors were noted along with other symptoms related to bowel or micturition habits, bleeding per vagina, features of preeclampsia and perception of foetal movement. A detailed obstetrical, gynaecological, medical and surgical history was taken. Each patient was then subjected to general and abdominal examination keeping in mind that the typical signs might be absent, obstetrical assessment, vaginal and/or rectal examination if indicated. Women with labour pains were excluded from the study. Depending on the case, the necessary investigations apart from the routine antenatal tests were carried out such as blood grouping and cross matching, liver and renal function tests, serum electrolytes, serum lipase and amylase, blood coagulation profile, peripheral smear, swab or blood culture, urine routine examination and culture sensitivity, ECG in atypical epigastric pain. Ultrasonography was performed in all cases to aid in obstetrical as well as surgical diagnosis. MRI was done when feasible or when diagnosis was not certain. Case management was individualised, and a multidisciplinary approach was taken. Emergency surgery was performed if indicated; however, the second trimester was usually preferred for surgical intervention. All women were followed up till the time of discharge. Data was analysed with Microsoft Excel.

\section{RESULTS}

A total of 55 women presenting with acute pain abdomen during pregnancy were studied. Table 1 shows the demographic characteristics. Most of the women (41.8\%) were of the age group of 25 to 31 years. The mean age was 26.31 years with a standard deviation of 4.1 years. $49.1 \%$ were Muslims, $20 \%$ were Hindus and the rest were Christians. 34.5\% were booked cases. $81.8 \%$ were from rural areas. An equal number of women (36.4\% each) presented with pain in the second and third trimester of pregnancy.

The presenting clinical features have been discussed in Table 2. While pain was a constant symptom in all cases, diminished appetite, nausea and bleeding per vagina were the other frequently associated symptoms. $89.1 \%$ women had a history of pain of less than 24 hours duration. $45.5 \%$ had diffuse abdominal pain, while $40 \%$ and $14.5 \%$ had pain localised to lower and upper abdomen respectively. $87.3 \%$ complained of continuous dull pain, while the rest had intermittent colicky pain. Anaemia (54.5\%) and hypotension (49.1\%) were the common associated findings.

Table 3 shows the diagnosis. 29 (52.7\%) women were diagnosed to have an obstetrical cause of pain, while in 26 $(47.3 \%)$ women the cause of pain abdomen was nonobstetrical. The common obstetrical causes were ectopic pregnancy, miscarriage, molar gestation and ruptured uterus. The common non-obstetrical causes included acute appendicitis, acute cholecystitis and ureteric colic.

Table 4 outlines the management. $82.8 \%$ of the women where pain was attributed to obstetrical cause required surgical management. Amongst the 26 cases with nonobstetrical origin of pain conservative management was done in $18(69.2 \%)$ women, while $8(30.8 \%)$ underwent surgery. Of these, laparotomy was performed in 5 women ( 2 for acute appendicitis, 2 for ovarian torsion, 1 for blunt trauma with splenic rupture) and laparoscopy was done in 3 women ( 2 for acute appendicitis, 1 for acute cholecystitis). Number of surgeries carried out in the second trimester were significantly higher $(\mathrm{p}<0.05)$.

The complications among women with non-obstetrical abdominal pain have been shown in Table 5. It included wound infection in 1 (Had laparotomy for acute appendicitis) and preterm labour in 1 (Had laparotomy for blunt trauma) amongst those treated surgically; preterm labour in 2 (Both had urinary tract infection) and intrauterine foetal death in 1 
(Diagnosed with acute pancreatitis) amongst those managed conservatively.

\begin{tabular}{|c|c|c|}
\hline Demographic Variable & Number & Percentage \\
\hline Age & & \\
\hline 18 to 24 years & 18 & 32.7 \\
\hline 25 to 31 years & 23 & 41.8 \\
\hline 32 to 38 years & 14 & 25.5 \\
\hline \multicolumn{3}{|l|}{ Religion } \\
\hline Muslim & 27 & 49.1 \\
\hline Hindu & 20 & 36.4 \\
\hline Christian & 8 & 14.5 \\
\hline \multicolumn{3}{|l|}{ Socioeconomic Status } \\
\hline Rural & 45 & 81.8 \\
\hline Urban & 10 & 18.2 \\
\hline \multicolumn{3}{|l|}{ Booked/ Unbooked Status } \\
\hline Booked & 19 & 34.5 \\
\hline Unbooked & 36 & 65.5 \\
\hline \multicolumn{3}{|l|}{$\begin{array}{c}\text { Gestational Age at Initial } \\
\text { Presentation }\end{array}$} \\
\hline 0 to 12 weeks & 15 & 27.2 \\
\hline$>12$ weeks to 28 weeks & 20 & 36.4 \\
\hline$>28$ weeks to 40 weeks & 20 & 36.4 \\
\hline
\end{tabular}

\begin{tabular}{|c|c|c|}
\hline Clinical Presentation & Number & Percentage \\
\hline Symptoms & & \\
\hline Abdominal pain & 55 & 100 \\
\hline Diminished appetite & 25 & 45.5 \\
\hline Nausea & 18 & 32.7 \\
\hline Bleeding per vagina & 15 & 27.3 \\
\hline Increased urinary frequency & 10 & 18.2 \\
\hline Backache & 10 & 18.2 \\
\hline Breathing difficulty & 4 & 7.3 \\
\hline Diarrhoea & 2 & 3.6 \\
\hline Constipation & 2 & 3.6 \\
\hline Duration of Symptoms & & \\
\hline$<24$ hours & 49 & 89.1 \\
\hline$>=24$ hours & 6 & 10.9 \\
\hline Location of Pain & & \\
\hline Upper abdomen & 8 & 14.5 \\
\hline Lower abdomen & 22 & 40 \\
\hline Diffuse & 25 & 45.5 \\
\hline Nature of Pain & & \\
\hline Continuous, dull & 48 & 87.3 \\
\hline Intermittent, colicky & 7 & 12.7 \\
\hline Associated Findings & & \\
\hline Anaemia & 30 & 54.5 \\
\hline Hypotension & 27 & 49.1 \\
\hline Hypertension & 2 & 3.6 \\
\hline Jaundice & 1 & 1.8 \\
\hline Diabetes mellitus & 1 & 1.8 \\
\hline
\end{tabular}

\begin{tabular}{|c|c|c|c|c|c|c|}
\hline Diagnosis & $1^{\text {st }}$ Trimester & $2^{\text {nd }}$ Trimester & $3^{\text {rd }}$ Trimester & Total & $\begin{array}{c}\text { Percentage of all } \\
\text { Cases }\end{array}$ & \\
\hline Obstetrical Cause & & & & & & $\begin{array}{c}\text { Percentage of } \\
\text { all Obstetrical } \\
\text { Causes }\end{array}$ \\
\hline Ectopic pregnancy & 7 & 1 & - & 8 & 14.5 & 27.6 \\
\hline Abortion & 4 & 2 & - & 6 & 10.9 & 20.7 \\
\hline Molar pregnancy & - & 5 & - & 5 & 9.1 & 17.2 \\
\hline Ruptured uterus & - & - & 5 & 5 & 9.1 & 17.2 \\
\hline Abruptio placentae & - & - & 3 & 3 & 5.5 & 10.3 \\
\hline Acute polyhydramnios & - & 1 & 1 & 2 & 3.6 & 6.9 \\
\hline Non-Obstetrical Cause & & & & & & $\begin{array}{l}\text { Percentage of } \\
\text { all Non- } \\
\text { Obstetrical } \\
\text { Causes }\end{array}$ \\
\hline Acute appendicitis & 1 & 3 & 1 & 5 & 9.1 & 19.2 \\
\hline Acute cholecystitis & - & 2 & 2 & 4 & 7.2 & 15.4 \\
\hline Ureteric colic & 1 & 1 & 2 & 4 & 7.2 & 15.4 \\
\hline $\begin{array}{l}\text { Acute urinary tract infection } \\
\text { Acute pancreatitis }\end{array}$ & 1 & 1 & 1 & 3 & 5.5 & 11.5 \\
\hline Intestinal obstruction & - & - & 2 & 2 & 3.6 & 7.7 \\
\hline Acute peptic ulcer & - & 1 & 1 & 2 & 3.6 & 7.7 \\
\hline Torsion of ovarian tumour & 1 & - & 1 & 2 & 3.6 & 7.7 \\
\hline $\begin{array}{c}\text { Blunt trauma } \\
\text { (Splenic rupture })\end{array}$ & - & 2 & - & 2 & 3.6 & 7.7 \\
\hline Red degeneration of uterine & - & - & 1 & 1 & 1.8 & 3.8 \\
\hline fibroid & - & 1 & - & 1 & 1.8 & 3.8 \\
\hline \multicolumn{7}{|c|}{ Table 3. Diagnosis } \\
\hline
\end{tabular}




\begin{tabular}{|c|c|c|}
\hline Management & Number & $\begin{array}{c}\text { Percentage of } \\
\text { obstetrical causes }\end{array}$ \\
\hline $\begin{array}{c}\text { Pain due to } \\
\text { obstetrical cause }\end{array}$ & & 17.2 \\
\hline Conservative & 5 & 82.8 \\
Surgical & 24 & $\begin{array}{c}\text { Percentage of non- } \\
\text { obstetrical causes }\end{array}$ \\
\hline Pain due to non- & & 69.2 \\
obstetrical cause & 18 & 30.8 \\
\hline Conservative & 8 & 19.2 \\
Surgical & 5 (3-2nd trimester, \\
Laparotomy & $2-3^{\text {rd trimester })}$ & 11.5 \\
Laparoscopy & 3 (3-2nd trimester) & \\
\hline \multicolumn{3}{|c|}{ Table 4. Management } \\
\hline
\end{tabular}

\begin{tabular}{|c|c|}
\hline Complications & Number \\
\hline Following surgical management & \\
Wound infection & 1 \\
Preterm labour & 1 \\
Following conservative management & \\
Preterm labour & 2 \\
Intrauterine foetal death & 1 \\
\hline \multicolumn{2}{|c|}{ Non-Obstetrical Cause } \\
\hline
\end{tabular}

\section{DISCUSSION}

The incidence of acute abdomen during pregnancy is 1 in 500-635 pregnancies.[14] The frequency of non-obstetrical acute abdomen is $0.39 \%$, mostly multifactorial. $0.2 \%$ to $1.0 \%$ of all pregnant women require non-obstetrical general surgery.[15] Appendicitis is the most common cause of acute abdomen during pregnancy[14,16] occurring with a usual frequency of 1 in 500 - 2000 pregnancies, which amounts to $25 \%$ of operative indications for non-obstetric surgery during pregnancy.[14] It affects as many as 1 in 766 pregnancies.[17,18] The incidence of acute appendicitis during pregnancy is 1 in every 1,500 , while approximately $4.5 \%$ of pregnant women have asymptomatic cholelithiasis and $0.05 \%$ acute cholecystitis.[13] Upto $40 \%$ of these patients will require surgery during pregnancy.[13] Asymptomatic stones are seen in $3.5 \%$ to $10 \%$ of pregnancies, while the incidence of gallbladder disease in pregnancy is $0.05 \%$ to $0.3 \%$. It is recommended to perform laparoscopic cholecystectomy in the first, second and early third trimester if indicated, because it is safe for both mother and the foetus.[19] Bowel obstruction in pregnancy is uncommon with a prevalence of 1 in 2500 to 16,709 deliveries.[20]

The non-obstetric causes of acute abdomen in pregnancy in one study[21] were biliary ascariasis (28\%), peptic ulcer disease $(24 \%)$, acute urinary tract infection $(10 \%)$, acute pyelonephritis $(6 \%)$, acute gastroenteritis $(6 \%)$, acute cholecystitis (6\%), acute appendicitis (6\%), acute pancreatitis $(2 \%)$, choledocholithiasis $(3 \%)$, ovarian solid mass (2\%), twisted ovarian cyst (2\%), renal colic (4\%) and renal calculus $(1 \%)$.

Laparoscopic approach is safe and effective in the diagnosis and treatment of acute abdominal pathology during pregnancy.[2,13] The advantages over conventional open surgery have made many surgeons and gynaecologists change their criteria in favour of laparoscopy and this is now often their first choice of treatment.[13]

Unal A et al[22] in their study of 20 patients requiring surgery during pregnancy found the mean age to be 32 years with a significant higher rate of emergency surgery in the second trimester $(\mathrm{p}<0.05)$ similar to our study. $100 \%$ presented with abdominal pain, while $80 \%$ had nausea. Ultrasonographic evaluation was done in all women, while MR imaging was done in 30\% women. USG and MRI findings were found to be consistent with surgical findings in 55\% and $83 \%$ cases respectively. Commonest diagnosis was appendicitis (30\%) followed by small bowel obstruction. The postoperative complications were wound infection $(10 \%)$, preterm delivery (5\%), paralytic ileus (5\%) and foetal loss, almost similar to our study.

In one study, it was noted that foetal loss after laparotomy in pregnancy was $23 \%$ and was more likely in the presence of peritonitis or when surgery on the ovary was done in the first trimester.[23]

Surgical delay due to delayed diagnosis results in increased maternal morbidities $(p<0.05)$ and poor foetal outcome; better perinatal outcome $(p<0.001)$ and decreased maternal morbidity $(p<0.05)$ are seen in those with early surgical intervention.[15]

\section{CONCLUSION}

Acute abdomen during pregnancy is an entity commonly encountered in obstetrical practice. Precise diagnosis is often difficult. The differential diagnosis should be kept in mind. Timely judicial management with the aid of surgeons and physicians is needed to tackle such cases.

\section{REFERENCES}

[1] Chandraharan E, Arulkumaran S. Acute abdomen and abdominal pain in pregnancy. Obstet Gynec \& Reprod Med 2008;18(8):205-12.

[2] Augustin G, Majerovic M. Non-obstetrical acute abdomen during pregnancy. Eur J Obstet Gynecol Reprod Biol 2007;131(1):4-12.

[3] Sivanesaratnam V. The acute abdomen and the obstetrician. Baillieres Best Pract Res Clin Obstet Gynaecol 2000;14(1):89-102.

[4] Bøe HA, Bjerklund JT. Acute abdomen in pregnancy. Diagnosis of surgical causes. Tidsskr Nor Laegeforen 1996;116(5):600-3.

[5] Coleman MT, Trianfo VA, Rund DA. Non-obstetric emergencies in pregnancy: trauma and surgical conditions. Am J Obstet Gynecol 1997;177(3):497-502.

[6] Woodfield CA, Lazarus E, Chen KC, et al. Abdominal pain in pregnancy: diagnoses and imaging unique to pregnancy - review. American Journal of Roentgenology 2010;194(Suppl 6):WS14-WS30.

[7] Mayer IE, Hussain H. Abdominal pain during pregnancy. Gastroenterol Clin North Am 1998;27(1):1-36.

[8] Cormier CM, Canzoneri BJ, Lewis DF, et al. Urolithiasis in pregnancy: current diagnosis, treatment and pregnancy complications. Obstet Gynecol Surv 2006;61(11):733-41.

[9] Ryan JP, Pellecchia D. Effect of ovarian hormone pretreatment on gallbladder motility in vitro. Life Sci 1982;31(14):1445-9.

[10] Lemine $M$, Collet $M$, Brettes JP. Abdominal emergencies and pregnancy. Rev Fr Gynecol Obstet 1994;89(11):553-9. 
[11] Kilpatrick CC, Monga M. Approach to the acute abdomen in Pregnancy. Obstetrics and Gynecology Clinics North Am 2007;34(3):389-402.

[12] Firstenberg MS, Malangoni MA. Gastrointestinal surgery during pregnancy. Gastroenterol Clin North Am 1998;27(1):73-88.

[13] Mui LW, Lee HK, Malhotra R. MRI evaluation of acute abdominal pain in the pregnant patient. J Am Osteopath Coll Radiol 2015;4(4):12-9.

[14] Sánchez WA, Martínez GD, Itzkovich RN, et al. Analysis of the increasing role of laparoscopy in the management of acute abdomen in pregnancy. Gynecol Obstet Mex 2001;69:422-30.

[15] El-Amin AM, Al-Shehri YM, Zaki ZM, et al. Acute abdomen in pregnancy. Int $\mathrm{J}$ Gynaecol Obstet 1998;62(1):31-6.

[16] Parangi S, Levine D, Henry A, et al. Surgical gastrointestinal disorders during pregnancy. Am J Surg 2007;193(2):223-32.

[17] Sharp HT. The acute abdomen during pregnancy. Clin Obstet and Gynecol 2002;45(2):405-13.
[18] Singh AK, Desai H, Novelline RA. Emergency MRI of acute pelvic pain: MR protocol with no oral contrast. Emerg Radiol 2009;16(2):133-41.

[19] Andersen B, Nielsen TF. Appendicitis in pregnancy: diagnosis, management and complications. Acta Obstet Gynecol Scand 1999;78(9):758-62.

[20] Cosenza CA, Saffari B, Jabbour N, et al. Surgical management of biliary gallstone disease during pregnancy. Am J Surg 1999;178(6):545-8.

[21] Hayanga AJ, Bass-Wilkins K, Bulkley GB. Current management of small-bowel obstruction. Adv Surg 2005;39:1-33.

[22] Haque M, Kamal F, Chowdhury S, et al. Non obstetric causes and presentation of acute abdomen among the pregnant women. J Family Reprod Health 2014;8(3):117-22.

[23] Saunders P, Milton PJ. Laparotomy during pregnancy: an assessment of diagnostic accuracy and fetal wastage. Br Med J 1973;3(5872):165-7. 